\title{
Work Form Affects Maximum Oxygen Uptake for One Year in Workers
}

\author{
Takayoshi HIRAI ${ }^{1 *}$, Yukinori KUSAKA ${ }^{1}$, Narufumi SUGANUMA ${ }^{2}$, \\ Akihiko $\mathrm{SEO}^{3}$ and Yoshie TOBITA ${ }^{4}$
${ }^{1}$ Division of Environmental Health, Department of International and Social Medicine, School of Medicine, University of Fukui, 23-3 Matuokasimoaizuki, Eiheiji-cho, Yoshida-gun, Fukui 910-1193, Japan
${ }^{2}$ Department of Environmental Medicine, Kochi Medical School, Oko-cho Kohasu, Nankoku-shi, Kochi 783-8505, Japan
${ }^{3}$ Department of Production and Information Systems Engineering, Tokyo Metropolitan Institute of Technology, 6-6 Asahigaoka, Hino City, Tokyo 191-0065, Japan
${ }^{4}$ Fukui Occupational Health Center, 1-3-10 Nikkou, Fukui city, Fukui 910-0029, Japan

Received March 7, 2007 and accepted September 21, 2010

Published online in J-STAGE January 25, 2011

\begin{abstract}
Our previous study suggested that the work form is related to the maximum oxygen uptake ( $\left(\mathrm{V}_{2} \mathrm{max}\right)$. Therefore, we test the hypothesis by a longitudinal study that, besides these lifestyle-related factors, the work form increases $\dot{\mathrm{V}}_{2}$ max among workers. Seven hundred and ninety nine males aged $37.1 \pm 10.6$ and 395 females aged $37.7 \pm 10.5$ (range: 20 to $59 \mathrm{yr}$ old), who participated in The Total Health Promotion Plan (THP) at their respective workplaces twice in one year from 1997 to 1998 , were selected. Data on $\dot{\mathrm{V}} \mathrm{O}_{2}$ max were analyzed for age, systolic blood pressure (SBP), body mass index (BMI), work form (sedentary, standing, and ambulatory), exercise, and smoking. Age and the baseline variables for $\mathrm{BMI}$ and for $\dot{\mathrm{V}}_{2}$ max showed significant negative relationships with a change in $\dot{\mathrm{V}} \mathrm{O}_{2} \mathrm{max}$ in males and females. Further, a change in the BMI showed a significant negative relationship with a change of $\dot{\mathrm{V}} \mathrm{O}_{2} \mathrm{max}$ in males. However, exercise habit and an ambulatory work form showed significant positive relationships with a change of $\dot{\mathrm{V}}_{2} \mathrm{max}$ in males. It was suggested that after adjusting for other factors in males, an ambulatory work form may be associated with an increase in $\dot{\mathrm{V}} \mathrm{O}_{2} \max$ in one year.
\end{abstract}

Key words: $\dot{\mathrm{V}} \mathrm{O}_{2} \mathrm{max}$, Work load, Work form, Physical activity, Exercise, Lifestyle, BMI, Blood pressure, Longitudinal Study

\section{Introduction}

As a consequence of the WHO Ottawa Charter of 1986, the Industrial Safety and Health Law was revised in Japan in 1988. It prescribes that the execution of health promotion measures for workers is an obligation of employers. In line with this, the Total Health Promotion Plan (THP) was instituted ${ }^{1)}$. The THP includes not only medical examination, but also investigation of the lifestyle, and assessment of physical

*To whom correspondence should be addressed.

E-mail: thirai@u-fukui.ac.jp fitness. Determination of the maximal oxygen uptake $\left(\dot{\mathrm{V}}_{2} \mathrm{max}\right)$ as an indication of whole-body endurance is included in physical fitness assessment. Based on these results, guidance for health care and psychological counseling are provided to employees.

It has been reported that $\dot{\mathrm{V}}_{2}$ max is influenced by lifestyle-related factors such as exercise and smoking $^{2-12)}$.

Previous research reported that a fall in $\mathrm{VO}_{2}$ max is closely associated with cardiovascular system disorders, such as heart disease and hypertension $\left.{ }^{7}, 10,13-19\right)$.

Based on this evidence and from the viewpoint of preventive medicine, $\dot{\mathrm{VO}}_{2}$ max is being used as a health 
index in THP.

In 1945, when work loads were intense, in order to conserve strength, Brody ${ }^{20)}$ proposed that work intensity during the working shift should not exceed 50\% of $\dot{\mathrm{V}}_{2} \mathrm{max}$. Since then, mechanization in the work place and automation have advanced, and, further, as a result, work intensity in recent years has decreased markedly and industries with a low work intensities tend to prevail in developed countries. According to Andersen $^{21)}, \mathrm{V}_{2}$ max measurements among male government officials, white-collared workers, and university students were significantly higher than those in bluecollared workers and the unemployed. His interpretation was that physical activity in persons of the upper class was realized largely through leisure-time activity. Furthermore, he proposed that gymnastics classes at schools for occupational training improved the lifestyle quality and endurance of students.

The work form, which is of a low intensity in many industries, and working duration, which is an average of $8 \mathrm{~h}$ per day for five to six days per week, may affect $\dot{\mathrm{V}}_{2}$ max among workers over a protracted period of time. To analyze the relationship between the work form and $\dot{\mathrm{V}}_{2} \max$ for the purposes of occupational health, work form (sedentary, standing, and ambulatory) was chosen as an indication of physical activity in the author's previous study ${ }^{12)}$.

The most popular reference for the categorization of physical activity levels is the 4-point classification system in the Japanese guideline developed by the present authors $^{22)}$ and Nagaya et $a l^{23)}$. Using this 4-scale categorization, and a self-judged 3-point work activity level (weak, moderate, and strong) a significant relationship between work activity and serum lipids was noted.

By means of modifying the Japan Ministry 4-point classification system, Kishida et al. ${ }^{24)}$ considered the duration and a combined walk and work form, and categorized the work intensity into 3 categories (light, moderate, and heavy). They then showed a significant effect of work load intensity on $\dot{\mathrm{V}}_{2}$ max. Suenaga ${ }^{25}$, for the purpose of assessing the pattern of physical activity more precisely, further revised the usual Japan Government 4-point classification, into 6 groups: 1) sedentary, 2) sedentary and walking, 3) sedentary and brisk walking, 4) sedentary and exercise, 5) active with no regular job but spending spare time actively and, 6) active with no regular job but spending spare time actively with exercise. In the study of Suenaga ${ }^{25)}$, all groups showed significantly higher values of $\dot{\mathrm{O}}_{2} \max$ than the sedentary group.

In order to consider the effect of the work load on $\mathrm{V}_{2}$ max, we took the work form as another measure of physical activity, independent of exercise hab- its $\left.^{7}, 11,12,23,24,27\right)$. We categorized the work form into "sedentary", "standing", and "ambulatory", in order of increasing work load intensity ${ }^{12}$.

Our present study is similar to these three preceding studies ${ }^{23-25)}$ in terms of the terminology used for categorizing the work load. There have been only two studies ${ }^{19}, 22$ addressing work intensity with regard to $\dot{\mathrm{VO}}_{2}$ max. Our study addressed the relationship between the work form and $\mathrm{V}_{2}$ max using the 3-scale category of work intensity, similarly to these two studies.

In our cross-sectional study ${ }^{12)}$ using a multiple regression model, both categories of work form, standing and ambulatory, were shown to be associated independently with a high $\dot{\mathrm{V}}_{2} \max$. Moreover, the regression coefficients for the two were proportional to the order of intensity.

The objective of this study was to analyze continuous data obtained over one year on $\mathrm{VO}_{2}$ max recorded in THP.

We also examined whether the work form and the following factors affect $\Delta \dot{\mathrm{V}}_{2} \max$ (value at the second measurement minus that at the first measurement) for one year: age, systolic blood pressure (SBP) as a physiological factor related o the cardiovascular system, body mass index (BMI) as a physical factor, smoking, exercise habit, and history. These factors were examined among those whose lifestyle and exercise habits did not change over the study period.

\section{Subjects}

According to the Industrial Health and Safety Law, the Japan Assembly approved the THP policy in association with the budget. In line with this, the Japan Industrial Safety and Health Association (JISHA) drew up a contract with the Ministry of Health, Labor and Welfare to perform examinations. The Safety and Health Committee within each enterprise, which is composed of employers, industrial physicians, and representatives of employees and is set up according to the Industrial Safety and Health Law, also gave approval.

The management staff of the companies fully explained THP to all subjects. The staff of Fukui Health Service Association also fully explained to all subjects the details of measurements and obtained oral consent at the time of the examination.

In line with this, 1,534 male and 610 female workers (range: 20 to $59 \mathrm{yr}$ old) underwent medical examinations, investigation of the lifestyle, and assessment of physical fitness for the THP at Fukui Health Service Association twice over a one-year period between 1997 and 1998. Subjects meeting the following 2 criteria were selected: being free from contraindications for the 
Table 1. Number (\%) of subjects by work form, exercise habit, exercise history, and smoking according to gender

\begin{tabular}{ccc}
\hline & $\begin{array}{c}\text { Male (N=799) } \\
\text { Number (\%) }\end{array}$ & $\begin{array}{c}\text { Female }(\mathrm{N}=395) \\
\text { Number (\%) }\end{array}$ \\
\hline Sedentary $^{\mathrm{a}}$ & $264(33)$ & $250(62)$ \\
Standing $^{\mathrm{b}}$ & $144(20)$ & $63(16)$ \\
Ambulatory $^{\mathrm{c}}$ & $391(47)$ & $82(22)$ \\
\hline Exercise habit & $184(23)$ & $67(17)$ \\
No exercise habit & $615(73)$ & $328(83)$ \\
\hline Exercise history & $344(43)$ & $190(48)$ \\
No exercise history & $455(57)$ & $205(52)$ \\
\hline Smoking & $453(58)$ & $36(9)$ \\
No smoking history & $346(42)$ & $359(91)$
\end{tabular}

aWork form: Sedentary, ${ }^{\text {bWork form: Standing, }{ }^{\mathrm{c}} \text { Work form: }}$ Ambulatory.

test and capable of undergoing the exercise test without any problems, and currently receiving no medication or therapy. This produced 1,436 male and 583 female workers for the study.

On the assumption that the physical strength level of these workers was in the normal range, those whose $\dot{\mathrm{V}} \mathrm{O}_{2}$ max was separated by $3 \sigma$ or more from the means of the distribution of $\mathrm{VO}_{2} \max$ in each gender and age group $(10 \mathrm{yr})$ were excluded. Finally, there were 1,416 male (average age \pm SD: $36.8 \pm 10.7 \mathrm{yr}$ ) and 569 females (average age \pm SD: $37.7 \pm 10.5 \mathrm{yr}$ ) subjects.

In addition, those whose work form, exercise, and smoking habits did not change from the first to second examination were selected. Finally, the subjects consisted of 799 males (average age \pm SD: $37.1 \pm 10.6 \mathrm{yr}$ ) and 395 females (average age \pm SD: $37.7 \pm 10.5 \mathrm{yr}$ ).

Table 1 shows the characteristics of subjects by gender.

\section{Methods}

The following factors which may affect $\mathrm{V}_{2}$ max were chosen for analysis: age, SBP $(\mathrm{mmHg})$ as one of the physiological factors, BMI as one of the physical factors (a physical index computed from the height and weight), work form as an index of work intensity, i.e., sedentary, standing, or ambulatory, exercise habit and exercise history as part of physical activity factors, and smoking as a lifestyle-related factor.

Changes in parameters, i.e., $\Delta \dot{\mathrm{VO}}_{2} \max , \Delta \mathrm{SBP}(\mathrm{mmHg})$ (value at the second minus that at the first measurement), and $\triangle \mathrm{BMI}$ (value at the second minus that at the first measurement) were identified by subtracting the value obtained at the first examination from that at the second, and positive values were considered as increases, while negative ones were decreases.
$\dot{\mathrm{V}}_{2}$ max was measured using a bicycle ergometer in the same way as in our cross-sectional study ${ }^{12)}$. The blood pressure was measured using an automatic scale as in our cross-sectional study.

We also categorized exercise habit, exercise history, work form, and smoking habit in the same way as in our cross-sectional study, as follows:

"Exercise habit" was assessed on a 5-point scale based on frequency: 1) performed almost every day, 2) 3 or 4 times per week, 3) 1 or 2 times per week, 4) 1 or 2 times per month, 5) only occasional exercise. The responses were dichotomized: the scaling of 1), 2), and 3) was defined as having an "exercise habit", and 4) and 5) were defined as "no exercise habit".

Responses to this question were categorized into two because, according to the literature ${ }^{19)}$, effects on health, exercise twice a week has beneficial where as one time or less per month means nothing. An answer (5-point scale: 3). Indicating a habit of two times a week was defined as an "exercise habit", although once a week was included. Our previous report adopted this criterion, and the scaling was continuous in the present study ${ }^{12)}$

"Exercise history" was assessed based on exercise experience: 1) walking, 2) jogging and running, 3) cycling, 4) swimming, 5) gymnastics, 6) healthy gymnastics and stretching, 7) ball games, such as tennis and volleyball, 8) ball games, such as baseball and softball, 9) mountain climbing and hiking, and 10) golf. The participants chose a maximum of three items from these ten. These responses were dichotomized as follows employing the same criteria as before ${ }^{12)}$ : if one or more items were chosen, individuals were defined as having an "exercise history"; if no items were chosen, "no exercise history" was assigned.

As for the questionnaire of THP, the choice of the exercise item is varied. However, the number of years and exercise frequency of the exercise history are unknown. Therefore, I think that the scale only for exercise items is worthless as an index of "exercise history".

The work form was assessed on a 3-point scale based on the main physical posture during work time: 1) mostly sitting down, 2) mostly standing, and 3) mostly walking. These responses were trichotomized as "sedentary", "standing", and "ambulatory", respectively.

Smoking was assessed by the present smoking status: 1) smoker, and 2) non-smoker (including ex-smoker). These responses were dichotomized as either "smoker" or "non-smoker", respectively. 


\section{Statistical Analysis}

1) The significance of differences in the mean values of measurement parameters, i.e., $\mathrm{VO}_{2} \mathrm{max}$, SBP, and BMI, between the first and second measurements was analyzed by the paired $t$-test in each gender.

The significance of differences in the mean values of $\mathrm{VO}_{2}$ max by work form between the first and second measurements was analyzed by the paired $t$-test in each gender.

Differences were judged to be significant at $p<0.05$.

2) Simple correlation analysis of $\Delta \mathrm{VO}_{2}$ max with each of the ten factors was performed for each gender.

Correlation analyses with these quantitative variables, namely age, SBP, and BMI, were performed using Pearson's correlation analysis or Spearman's method when at least one of the variables was categorical.

Differences were judged to be significant at $p<0.05$.

3) Multiple regression analyses of $\Delta \dot{\mathrm{OO}}_{2}$ max as the dependent variable with the ten factors as independent variables were performed for each gender, as shown below.

We included age, SBP, and BMI as variables since they exhibited significant influences on $\dot{\mathrm{V}}_{2} \max$ in our previous cross-sectional study ${ }^{12)}$ using a multiple regression model. We chose work form, exercise habit, exercise history, and smoking in the same way as in our cross-sectional study. Furthermore, we added $\triangle \mathrm{SBP}$, $\triangle \mathrm{BMI}$, and baseline values for $\mathrm{V}_{2}$ max as independent variables. A dummy variable was used for work form, i.e., sedentary, standing, and ambulatory (standard variable: sedentary), and a variable of work form was forced into the regression equation. The other nine factors were applied using the stepwise method.

A variable was adopted when the $\mathrm{F}$ value was 2.00 or more. Differences were judged to be significant at $p<0.05$.

All statistical analyses were performed using the $11.0 \mathrm{~J}$ version of the SPSS statistical package for personal computers (SPSS Inc., Chicago, IL, USA).

\section{Results}

1) Comparison of the first and second values

Table 2 shows that the second BMI value was significantly higher than the first only in males. However, there were no significant differences between the first and second values for $\mathrm{V}_{2}$ max and SBP in either males or females.

Table 3 shows that there were no significant differences between the first and second values for work form ("sedentary", "standing", and "ambulatory") in either males or females.

2) Simple correlation analysis of factors to $\Delta \dot{\mathrm{VO}}_{2} \max$

Table 4 shows significant negative correlations between $\Delta \dot{\mathrm{VO}}_{2}$ max and the baseline $\dot{\mathrm{VO}}_{2}$ max for both males and females.

In males, a significant positive correlation between $\Delta \dot{\mathrm{V}}_{2} \mathrm{max}$ and the base line $\mathrm{BMI}$, and a significant negative correlation between $\Delta \dot{\mathrm{VO}}_{2}$ max and $\Delta \mathrm{BMI}$ were observed.

3) Multiple regression analysis of $\Delta \dot{V}^{2}$ max with the factors

Although age, exercise habit, and work form showed

Table 2. Physical characteristics of subjects by gender (Mean \pm SD)

\begin{tabular}{ccccc}
\hline Variables & \multicolumn{2}{c}{ Male $(\mathrm{N}=799)$} & \multicolumn{2}{c}{ Female $(\mathrm{N}=395)$} \\
\hline & $\begin{array}{c}\text { First } \\
\text { examination }\end{array}$ & $\begin{array}{c}\text { Second } \\
\text { examination }\end{array}$ & $\begin{array}{c}\text { First } \\
\text { examination }\end{array}$ & $\begin{array}{c}\text { Second } \\
\text { examination }\end{array}$ \\
Age $(\mathrm{yr})$ & $37.1 \pm 10.6$ & $38.1 \pm 10.6$ & $37.7 \pm 10.5$ & $38.7 \pm 10.5$ \\
$\dot{\mathrm{VO}}{ }_{2} \mathrm{max}(\mathrm{ml} / \mathrm{kg} / \mathrm{min})^{\mathrm{a}}$ & $37.8 \pm 5.9$ & $37.8 \pm 6.1$ & $31.5 \pm 5.6$ & $31.5 \pm 5.2$ \\
$\mathrm{SBP}(\mathrm{mmHg})^{\mathrm{b}}$ & $122.5 \pm 11.8$ & $123.1 \pm 12.2$ & $116.1 \pm 12.7$ & $115.2 \pm 13.1$ \\
$\mathrm{BMI}^{\mathrm{c}}$ & $22.6 \pm 2.7$ & $22.8 \pm 2.8^{*}$ & $21.1 \pm 2.5$ & $21.2 \pm 2.6$ \\
\hline
\end{tabular}

*Significant difference at $p<0.05$.

${ }^{\mathrm{a}} \dot{\mathrm{V}} \mathrm{O}_{2}$ max: Maximum oxygen uptake; ${ }^{\mathrm{b}} \mathrm{SBP}$ : Systolic blood pressure; ${ }^{\mathrm{c} B M I}$ : Body mass index.

Table 3. $\dot{\mathrm{V}} \mathrm{O}_{2}$ max of subjects with work form by gender (Mean \pm SD)

\begin{tabular}{ccccc}
\hline Work form & \multicolumn{2}{c}{ Male $(\mathrm{N}=799)$} & \multicolumn{2}{c}{ Female $(\mathrm{N}=395)$} \\
\hline & $\begin{array}{c}\text { First } \\
\text { examination }\end{array}$ & $\begin{array}{c}\text { Second } \\
\text { examination }\end{array}$ & $\begin{array}{c}\text { First } \\
\text { examination }\end{array}$ & $\begin{array}{c}\text { Second } \\
\text { examination }\end{array}$ \\
Sedentary $^{\mathrm{a}}$ & $36.6 \pm 6.1$ & $36.5 \pm 6.0$ & $31.4 \pm 5.7$ & $31.4 \pm 5.3$ \\
Standing $^{\mathrm{b}}$ & $37.9 \pm 5.9$ & $37.9 \pm 6.1$ & $30.7 \pm 5.5$ & $30.6 \pm 5.2$ \\
Ambulatory $^{\mathrm{c}}$ & $38.9 \pm 6.0$ & $39.0 \pm 6.2$ & $32.4 \pm 5.4$ & $32.5 \pm 5.1$ \\
\hline
\end{tabular}

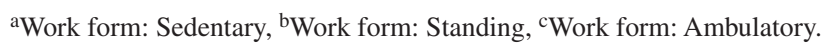


no correlation on simple correlation analysis, our previous cross-sectional study ${ }^{12}$ ) revealed the significant correlation of all these variables with $\dot{\mathrm{V}}_{2}$ max, both by simple correlation and multiple regression analyses.

Therefore, these variables were put into the multiple regression analysis.

Table 5 shows that the factors with significant positive standardized regression coefficients to $\Delta \mathrm{V}_{2}$ max in males were exercise habit (SRC 0.084) and the "ambu-

Table 4. Correlation analysis of $\Delta \dot{\mathrm{V}} \mathrm{O}_{2} \mathrm{max}^{\mathrm{a}}$ with age, SBP, BMI, exercise habit, exercise history, work form, and smoking by gender

\begin{tabular}{|c|c|c|}
\hline \multirow{2}{*}{ Variables } & \multicolumn{2}{|c|}{ Simple correlation coefficient } \\
\hline & Male & Female \\
\hline Age (yr) & 0.041 & -0.043 \\
\hline $\mathrm{SBP}(\mathrm{mmHg})^{\mathrm{b}}$ & 0.050 & 0.005 \\
\hline $\mathrm{BMI}^{\mathrm{c}}$ & $0.073 *$ & 0.019 \\
\hline Exercise habit & 0.005 & 0.021 \\
\hline Exercise history & 0.002 & -0.095 \\
\hline Work form & 0.042 & 0.024 \\
\hline Smoking & -0.016 & 0.044 \\
\hline$\dot{\mathrm{V}} \mathrm{O}_{2} \max (\mathrm{ml} / \mathrm{kg} / \mathrm{min})^{\mathrm{d}}$ & $-0.386^{*}$ & $-0.484 *$ \\
\hline$\Delta \mathrm{SBP}(\mathrm{mmHg})^{\mathrm{e}}$ & -0.049 & -0.049 \\
\hline$\Delta \mathrm{BMI}^{\mathrm{e}}$ & $-0.233 *$ & -0.086 \\
\hline
\end{tabular}

* Significant correlation at $p<0.05$.

${ }^{\mathrm{a}} \Delta \dot{\mathrm{VO}}_{2}$ max: Value at the second minus that at the first measurement,

bSBP: Baseline systolic blood pressure,

${ }^{\mathrm{C}} \mathrm{BMI}$ : Baseline body mass index,

${ }^{\mathrm{d}} \dot{\mathrm{O}}_{2}$ max: Baseline maximum oxygen uptake,

${ }^{\mathrm{e}} \Delta \mathrm{SBP}(\mathrm{mmHg}),{ }^{\mathrm{e}} \Delta \mathrm{BMI}$ : Value at the second minus that at the first measurement. latory" (SRC 0.074) work form. The factors with significant negative standardized regression coefficients to $\Delta \dot{\mathrm{VO}}_{2}$ max for males were the baseline $\dot{\mathrm{VO}}_{2}$ max (SRC -0.562), baseline BMI (SRC -0.243), $\triangle$ BMI (SRC -0.236 ), and age (SRC -0.097). Although the "standing" (SRC 0.042) work form showed a positive standardized regression coefficient, significance was not reached.

Although the work forms of "standing" and "ambulatory" showed positive standardized regression coefficients, significance was not observed for females.

Factors with significant negative standardized regression coefficients for females were the baseline $\dot{\mathrm{VO}}_{2}$ max (SRC -0.597), baseline BMI (SRC -0.199), and age (SRC -0.131 ) in this order of decreasing strength of association.

Exercise habit was not adopted as an independent variable in females. Exercise history was not adopted as an independent variable in either males or females.

\section{Discussion}

Relationship of $\dot{\mathrm{V}} \mathrm{O}_{2}$ max with the factors

Various lifestyle-related factors influence $\dot{\mathrm{V}}_{2}$ max. Previous studies have reported that aging, being overweight, and hypertension reduce $\dot{\mathrm{V}}_{2}$ max, whilst exercise increases it $\left.{ }^{7}, 9,11,24,26,27\right)$.

In our present research ${ }^{12)}$, simple correlation analysis revealed significant negative correlations between $\dot{\mathrm{V}} \mathrm{O}_{2} \mathrm{max}$, age, SBP, and BMI for both males and females. Significant positive correlations between $\dot{\mathrm{V}}_{2} \max$ and exercise habit were observed for both

Table 5. Multiple regression analysis of $\Delta \dot{\mathbf{V}} \mathbf{O}_{2} \max ^{\mathrm{a}}$ with age, BMI, exercise habit, work form, and smoking by gender

\begin{tabular}{|c|c|c|c|c|c|c|}
\hline \multirow[b]{2}{*}{ Variables } & \multicolumn{3}{|c|}{ Male } & \multicolumn{3}{|c|}{ Female } \\
\hline & $\begin{array}{l}\text { Standardized } \\
\text { regression } \\
\text { coefficient }\end{array}$ & $\begin{array}{c}\mathrm{T} \\
\text { values }\end{array}$ & $\begin{array}{c}p \\
\text { values }\end{array}$ & $\begin{array}{l}\text { Standardized } \\
\text { regression } \\
\text { coefficient }\end{array}$ & $\begin{array}{c}\mathrm{T} \\
\text { values }\end{array}$ & $\begin{array}{c}p \\
\text { values }\end{array}$ \\
\hline Age (yr) & -0.097 & -2.957 & $0.003^{*}$ & -0.131 & -2.730 & $0.007 *$ \\
\hline $\mathrm{BMI}^{\mathrm{b}}$ & -0.243 & -7.627 & $<0.001 *$ & -0.199 & -3.936 & $<0.001 *$ \\
\hline Exercise habit & 0.084 & 2.623 & $0.009^{*}$ & & & \\
\hline Standing ${ }^{c}$ & 0.042 & 1.191 & 0.234 & 0.020 & 0.407 & 0.684 \\
\hline Ambulatory $^{\mathrm{d}}$ & 0.074 & 2.088 & $0.037^{*}$ & 0.063 & 1.410 & 0.159 \\
\hline$\dot{\mathrm{V}} \mathrm{O}_{2} \max (\mathrm{ml} / \mathrm{kg} / \mathrm{min})^{\mathrm{e}}$ & -0.562 & -14.347 & $<0.001 *$ & -0.597 & -12.577 & $<0.001 *$ \\
\hline \multirow[t]{2}{*}{$\Delta \mathrm{BMI}^{\mathrm{f}}$} & -0.236 & -6.440 & $<0.001 *$ & & & \\
\hline & \multicolumn{3}{|c|}{$\begin{array}{c}\text { Adjusted for R square } \\
0.246^{*}\end{array}$} & \multicolumn{3}{|c|}{$\begin{array}{l}\text { Adjusted for R square } \\
0.284^{*}\end{array}$} \\
\hline
\end{tabular}

*Significant difference at $p<0.05$.

${ }^{\mathrm{a}} \Delta \dot{\mathrm{V}} \mathrm{O}_{2}$ max: Value at the second minus that at the first measurement,

bBMI: Baseline body mass index,

${ }^{\mathrm{c}}$ Work form: Standing, ${ }^{\mathrm{d}}$ Work form: Ambulatory,

${ }^{\mathrm{e}} \mathrm{VO}_{2}$ max: Baseline maximum oxygen uptake,

f $\triangle B M I$ : Value at the second minus that at the first measurement. 
males and females. Moreover, the multiple regression analysis showed significant relationships of age, exercise habit, and work form with $\dot{\mathrm{V}}_{2} \mathrm{max}^{12)}$. Although simple analysis did not show the significance of these variables, multiple regression analysis could adjust for these variables. These variables presumably confounded each other in the simple analysis.

Suenaga ${ }^{25)}$ reported that, at five years or more after stopping an exercise habit, there was a significant negative partial regression coefficient between $\dot{\mathrm{V}}_{2}$ max and years since ceasing exercising. We found no significant relation between $\Delta \dot{\mathrm{VO}}_{2}$ max and exercise history by simple correlation analysis. Therefore, it was not adopted as an independent variable in multiple regression analysis.

The difficulty of quantifying an exercise history using a questionnaire of the THP is a limitation of the present study's precision. Previous research reported that smoking decreases $\left.\dot{\mathrm{V}}_{2} \max ^{9}, 11\right)$. According to acrosssectional study by Yamaji ${ }^{10)}$, there was no significant difference in $\dot{\mathrm{VO}}_{2}$ max between smokers and non-smokers. Although smoking was not shown to be related to $\dot{\mathrm{V}}_{2}$ max in a preceding cross-sectional study ${ }^{7}$ ), it was adopted as a significant negative factor in males in a longitudinal study ${ }^{11}$.

In our cross-sectional study ${ }^{12)}$, using multiple regression analysis, no significant correlation between these factors was detected in males. In contrast, in females, a positive standardized regression coefficient was detected and, thereafter, smoking was adopted as an independent variable. In our present longitudinal study, no significance was observed for the factor of smoking in either males or females. Therefore, the results for smoking are conflicting, so a long-term longitudinal study is desirable to clarify this.

\section{Physical work load}

Some research has been published on the relationship between work load and $\dot{\mathrm{VO}}_{2}$ max. Kishida et al. ${ }^{24)}$ demonstrated a significant positive partial correlation coefficient of 0.193 in males in their 30's between physical activity including work and $\mathrm{V}_{2}$ max. According to a report by Suenaga ${ }^{25)}, \dot{\mathrm{V}} \mathrm{O}_{2} \max$ of active middle-aged males was significantly higher than in those mainly seated during work.

Naito ${ }^{19)}$ reported that $\dot{\mathrm{V}} \mathrm{O}_{2} \max$ was high among standing workers. By measuring Metabolic Equivalents (METs), he attributed the large amount of energy expended for standing to the increase in $\mathrm{V}_{2} \max$. In these studies, exercise and work load were summed to calculate the total amount of physical activity.

In our previous study ${ }^{12)}$, exercise and work form were used as independent factors. Furthermore, the influence of age, baseline BMI, $\triangle \mathrm{BMI}$, baseline blood pressure, $\Delta$ blood pressure, exercise, and smoking were adjusted for each other in multivariate analysis, and we demonstrated through a follow-up study for one year in males that an ambulatory work form may be associated with an increase in $\dot{\mathrm{V}}_{2}$ max. In today's mechanized industry, it might positively affect fitness, namely $\mathrm{V}_{2}$ max.

Although the factors of an "ambulatory" work form in females showed positive standardized regression coefficients, significance was not observed. This may be because the actual working duration and intensity of moving or standing at work are different between males and females. For instance, a working time of more than 8 hours per day and somewhat heavy load are usually seen among males.

There is room for further investigation regarding this point as well.

\section{Study prospective}

To overcome the limitation of the one-year longitudinal study, a more long-term longitudinal study is required. The work intensity also needs to be quantitatively examined to further test the hypothesis that it contributes to the increase in $\dot{\mathrm{V}}_{2}$ max.

\section{Acknowledgements}

We thank the Fukui Preventive Medicine Association for offering valuable data and morally supporting the present study.

\section{References}

1) Nozaki S, Itokawa $Y$, Saito $K$, Sakurai H, Hirohata $T$ (2000) Labor health administration. New Hygiene and Public Health, 370-1, Nankoudo, Tokyo.

2) Kawabata K, Imaki M, Ohguri M, Kondo H, Hayashi Y, Tanada S (1997) Study on the relationship between lifestyles and maximal oxygen uptake in healthy adults. Jpn J Hyg 52, 470-4.

3) Blair SN, Kohi HW, Jr Paffenbarger RS, Clark DG, Cooper KH, Gibbons LW (1989) Phycical fitness and all cause mortality. A prospective study of healthy men and women. JAMA 262, 2395-401.

4) Blair SN, Cheng Y, Holder JS (2001) Is physical activity or physical fitness more important in defining health benefits? Med Sci Sports Exerc 33, S379-99.

5) Kokkinos PF, Fernhall B (1999) Physical activity and high density lipoprotein cholesterol levels. Sports Med 28, 307-14.

6) Lakka TA, Laukkanen JA, Rauramaa R, Salonen R, Lakka HM, Kaplan GA, Salonen JT (2001) Cardiorespiratory fitness and the progression of carotid atherosclerosis in middle aged men. Ann Intern Med 
134, 12-20.

7) Tobita Y, Otaki H, Kusaka Y, Iki M, Kajita E, Sato K (1995) Cross-sectional analysis on relationships between maximum oxygen uptake and risk factors for cardiovascular diseases. J Occup Health 37, 409-15.

8) Shephard RJ (2001) Absolute versus relative intensity of physical activity in a dose-response context. Med Sci Sports Exerc 33, S400-11.

9) Montoye HJ, Gayle R, Higgins M (1980) Smoking habits, alcohol consumption and maximal oxygen uptake. Med Sci Sports Exerc 12, 316-21.

10) Yamaji K (1994) Measurement of maximum oxygen uptake -indirect method-Yamaji K. Science of maximum oxygen uptake. 38-54, 186-90, Kyorinshoin, Tokyo.

11) Tobita Y, Kusaka Y, Otaki H, Hashizume K (2003) Factors affecting the estimated maximal oxygen uptake: a follow-up study of participants in the Total Health Promotion Plan. Environ Health Prev Med 8, 173-7.

12) Hirai T, Kusaka Y, Suganuma N, Seo A, Tobita Y (2006) Physical work load affects the maximum oxygen uptake. Ind Health 44, 250-7.

13) Montoye HJ, Block WD, Gayle R (1978) Maximal oxygen uptake and blood lipids. J Chron Dis 31, 111-8.

14) Twisk JWR, Kemper HCG, Mechelen WV, Post GB (1997) Which lifestyle parameters discriminate highfrom low-risk participants for coronary heart disease risk factors. Longitudinal analysis covering adolescence and young adulthood. Cardiovascular Risk 4, 393-400.

15) Samitz G, Bachl N (1991) Physical training programs and their effects on aerobic capacity and coronary risk profile in sedentary individuals. J Sports Med Phys Fit 31, 283-93.

16) Sedgwick AW, Thomas DW, Davies M (1993) Relationships between change in aerobic fitness and changes in blood pressure and plasma lipids in men and women. The "Adelaide 1000" 4-year follow up. J Clin Epidemiol 46, 141-51.

17) Cooper KH, Pollock ML, Martin RP, White SR, Linnerud AC, Jackson A (1976) Physical fitness lev- els vs selected coronary risk factors: a cross-sectional study. JAMA 236, 116-9.

18) Suzuki I, Yamada H, Sugiura T, Kawakami N, Shimizu H (1998) Cardiovascular fitness: physical activity and selected coronary heart disease risk factors in adults. J Sports Med Phys Fit 38, 149-57.

19) Naito $Y$ (1994) Relationship between physical activity and health examination variables in male workers -New methods to assess physical activity and their applications to epidemiologic research-. Jpn J Hyg 41, 706-19.

20) Brody S (1945) Bioenergetics and growth. 906, Rheinhold Publishing, New York.

21) Andersen LB (1996) Tracking of risk factors for coronary heart disease from adolescence to young adulthood with special emphasis on physical activity and fitness. Dan Med Bull 43, 407-18.

22) Energy and the nutrition information study group (1999) Recommended dietary allowances for Japanese: dietary reference intakes. 6th Ed., 31-47, Daiichishuppan, Tokyo.

23) Nagaya T, Takahashi A, Yokoyama M, Yoshida I, Okamoto Y (1991) Self-judged work activity level and lipid metabolism in young male adult. Ind Health 29, 123-8.

24) Kishida $T$, Inaba $R$, Iwata $H$ (1997) Relationships between maximal oxygen uptake $\left(\dot{\mathrm{V}}_{2} \mathrm{max}\right)$ and physical activity, blood pressure and serum lipids. Jpn J Hyg 52, 475-80.

25) Suenaga $T$ (2002) Classification of physical activity and health related variables in men. Jpn J Hyg 57, 513-21.

26) Blair SN, Haskell WL, Ho P, Paffenbarger Jr RS, Vranizan KM, Farquhar JW, Wood PD (1985) Assessment of habitual physical activity by a sevenday recall in a community survey and controlled experiments. Am J Epidemiol 122, 794-804.

27) Okamoto M, Suyama A, Morio S, Nakayama H (1989) Health and physical fitness indices (report II) assessment of habitual physical activity and exercise based on physical activity score. Nihon Koshu Eisei Zasshi 36, 783-9. 